\title{
Cost-effectiveness analysis of non-invasive vagus nerve stimulation for the treatment of chronic cluster headache
}

\author{
James Morris ${ }^{1 *}$, Andreas Straube ${ }^{2}$, Hans-Christoph Diener ${ }^{3}$, Fayyaz Ahmed ${ }^{4}$, Nicholas Silver ${ }^{5}$, Simon Walker ${ }^{1}$,
} Eric Liebler ${ }^{6}$ and Charly Gaul ${ }^{3,7}$

\begin{abstract}
Background: Cluster headache $(\mathrm{CH})$ is a debilitating condition that is generally associated with substantial health care costs. Few therapies are approved for abortive or prophylactic treatment. Results from the prospective, randomised, open-label PREVA study suggested that adjunctive treatment with a novel non-invasive vagus nerve stimulation (nVNS) device led to decreased attack frequency and abortive medication use in patients with chronic $\mathrm{CH}(\mathrm{cCH})$. Herein, we evaluate whether nVNS is cost-effective compared with the current standard of care (SoC) for $\mathrm{CCH}$.
\end{abstract}

Methods: A pharmacoeconomic model from the German statutory health insurance perspective was developed to estimate the 1-year cost-effectiveness of nVNS + SoC (versus SoC alone) using data from PREVA. Short-term treatment response data were taken from the clinical trial; longer-term response was modelled under scenarios of response maintenance, constant rate of response loss, and diminishing rate of response loss. Health-related quality of life was estimated by modelling EQ-5D ${ }^{\text {TM }}$ data from PREVA; benefits were defined as quality-adjusted life-years (QALY). Abortive medication use data from PREVA, along with costs for the nVNS device and abortive therapies (i.e. intranasal zolmitriptan, subcutaneous sumatriptan, and inhaled oxygen), were used to assess health care costs in the German setting.

Results: The analysis resulted in mean expected yearly costs of $€ 7096.69$ for nVNS + SoC and $€ 7511.35$ for SoC alone and mean QALY of 0.607 for nVNS + SoC and 0.522 for SoC alone, suggesting that nVNS generates greater health benefits for lower overall cost. Abortive medication costs were $23 \%$ lower with nVNS + SoC than with SoC alone. In the alternative scenarios (i.e. constant rate of response loss and diminishing rate of response loss), nVNS + SoC was more effective and cost saving than SoC alone.

Conclusions: In all scenarios modelled from a German perspective, nVNS was cost-effective compared with current SoC, which suggests that adjunctive nVNS therapy provides economic benefits in the treatment of $\mathrm{cCH}$. Notably, the current analysis included only costs associated with abortive treatments. Treatment with nVNS will likely promote further economic benefit when other potential sources of cost savings (e.g. reduced frequency of clinic visits) are considered.

Trial registration: Clinicaltrials.gov identifier NCT01701245, 030CT2012.

Keywords: Chronic cluster headache, Vagus nerve stimulation, Non-invasive, Cost-effectiveness, Germany, Pharmacoeconomics, United Kingdom

\footnotetext{
* Correspondence: james.morris@cogentia.co.uk

${ }^{1}$ Cogentia Healthcare Consulting Ltd., Richmond House, 16-20 Regent Street,

Cambridge CB2 1DB, UK

Full list of author information is available at the end of the article
} 


\section{Background}

Cluster headache $(\mathrm{CH})$ is a debilitating condition associated with intense pain and cranial autonomic symptoms, which cause marked disability [1]. The disorder adversely affects quality of life [2] and is associated with substantial health care costs (more than $€ 11,000$ per year) [3]. The condition can be chronic or episodic. Both direct costs (e.g. medication, clinic visits) and indirect costs (e.g. reduced work capacity) have been found to be substantially higher for patients with chronic $\mathrm{CH}(\mathrm{cCH})$ than for those with episodic $\mathrm{CH}$ [3]. Few drugs (e.g. subcutaneous [SC] sumatriptan, intranasal [IN] zolmitriptan, and dihydroergotamine [DHE] injection) are approved by various regulatory agencies for abortive treatment $[4,5]$. Lithium is approved for $\mathrm{CH}$ prophylaxis in Germany [6] and is used off-label in other areas. Other agents such as verapamil and topiramate are also used off-label despite a lack of rigorous, well-controlled studies to support their use in the prevention of $\mathrm{CH}$ attacks [7-9]. Although short-term methylprednisone therapy may be effective in $\mathrm{CH}$ prophylaxis, several safety concerns preclude its long-term use [8].

Vagus nerve stimulation (VNS) is a neuromodulatory technique that is well established for epilepsy and depression and has been applied to a variety of other disorders including Alzheimer disease, migraine, and $\mathrm{CH}$ [10-12]. It is thought to suppress pain through inhibition of vagal afferents in the trigeminal nucleus caudalis (TNC) [13] and by blocking or reversing increases in TNC glutamate levels [14]; VNS has also been implicated in modulation of the cholinergic anti-inflammatory pathway [15-17].

In an initial open-label study $(N=19)$, non-invasive vagus nerve stimulation ( $\mathrm{nVNS}$ ) was found to be effective in the prevention and treatment of $\mathrm{CH}$ [11]. Subsequently, a larger $(N=97)$, prospective, open-label, randomised study (PREVA [18]) evaluated the safety and efficacy of adjunctive treatment with a novel nVNS device (gammaCore) in patients with $\mathrm{cCH}$. In the PREVA trial, compared with standard of care (SoC) alone, adjunctive nVNS (nVNS + SoC) was associated with significantly greater decreases from baseline in the number of $\mathrm{CH}$ attacks per week and the use of abortive medications. Compared with SoC alone, nVNS + SoC was also associated with a significantly higher response rate (i.e. the proportion of participants with a $\geq 50 \%$ reduction from baseline in the number of $\mathrm{CH}$ attacks per week; $40 \%$ for $n V N S+$ SoC vs $8.3 \%$ for SoC alone, $P<0.001$ ) and significantly greater improvements from baseline in quality-of-life measures, with no serious treatmentrelated adverse events.

The present analysis was undertaken to quantify the economic impact of nVNS therapy in patients with $\mathrm{cCH}$. By developing a pharmacoeconomic model and applying it to data from the PREVA study, we evaluated whether nVNS is a cost-effective treatment option compared with the current standard practice in a European setting. Analysis using German costs is the focus of this paper because Germans represented the largest proportion of PREVA participants. To corroborate our findings and widen their applicability, we conducted a similar analysis using UK costs, which is briefly described in the Discussion section.

\section{Methods}

\section{Study design}

The principal data source for this analysis was the PREVA study (clinicaltrials.gov identifier NCT01701245), which compared the effectiveness of nVNS added to SoC with that of SoC alone as prophylactic therapy for $\mathrm{cCH}$. For each participant, SoC was individualised and typically included prophylactic medications (e.g. verapamil, lithium) and abortive agents (e.g. inhaled oxygen, triptans). The study design (Fig. 1) and methodology of PREVA have been described in detail previously [18]. The PREVA study was conducted in accordance with the principles and requirements of the Declaration of Helsinki, Good

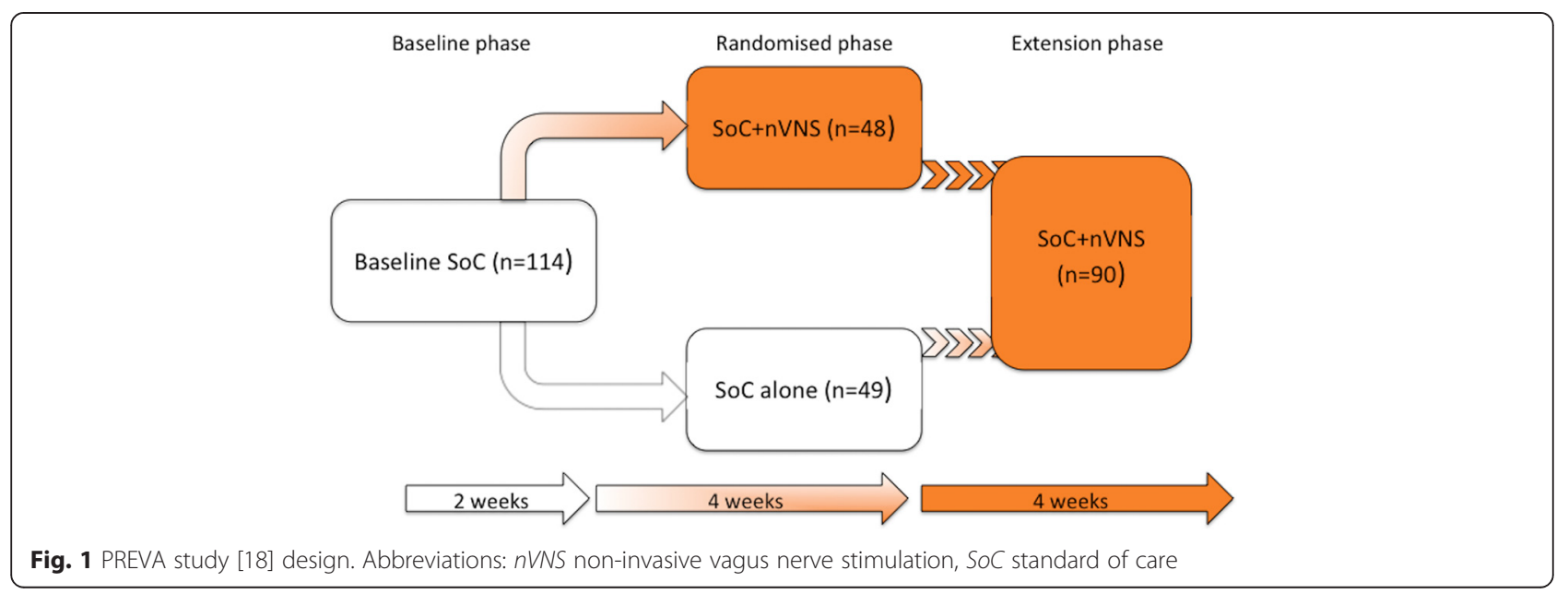


Clinical Practices, and clinical trial registration. All PREVA investigators obtained institutional review board approval, and all PREVA participants provided written informed consent.

\section{Model structure and parameter estimates}

Figure 2 depicts the 1-year model that was used to estimate the cost-effectiveness of adjunctive nVNS therapy from the German statutory health insurance perspective. Model parameter estimates were derived from data on the efficacy of nVNS and the use of abortive medications from the randomised phase of PREVA. Treatment response was defined as $\geq 50 \%$ reduction from baseline in the number of $\mathrm{CH}$ attacks per week. Beyond the randomised phase, responders in the SoC group were assumed to be non-responders, and non-responders in the nVNS $+\mathrm{SoC}$ group were assumed to discontinue prophylactic treatment with nVNS but continue use of abortive treatments. Four late responders in the $\mathrm{nVNS}+\mathrm{SoC}$ group (i.e. patients who were not classified as responders during the randomised phase but responded during the extension phase) were included as responders in the base case. An alternative scenario in which the 4 late responders were classified as non-responders was also modelled in a sensitivity analysis.

To estimate the probability of response in the base case analysis, subjects from the nVNS + SoC group who were responders throughout the extension phase were assumed to maintain this response until the end of the model time horizon ( 1 year). In addition to the base case analysis, 3 alternative scenarios were explored. An exponential survival curve function was fitted to data from patients in the nVNS + SoC group on the basis of their response statuses at the end of the randomised phase and at the end of the extension phase. In the first alternative scenario, the exponential function was used to predict patient response status beyond 4 weeks (i.e. beyond the randomised phase) assuming a constant monthly rate $(\sim 31 \%)$ of response loss throughout the course of the model. The second scenario was modelled assuming a diminishing rate of response loss; that is, the rate at which response was lost beyond 4 weeks (as predicted by the exponential function) was reduced by a fixed percentage $(10 \%)$ each month. In the final scenario, no patients in the SoC-alone group were assumed to have responded initially, and all other assumptions were the same as in the base case.

Benefits in this analysis were defined as qualityadjusted life-years (QALY). Health-related quality of life (HRQoL) for responders and non-responders was estimated by modelling EQ-5D ${ }^{\text {tax }}$ index data from PREVA in an ordinary least squares regression analysis to control for potential imbalances at baseline between treatment arms. Results from the regression analysis suggested that response was associated with an increase of 0.2366 in EQ-5D index score and that nVNS therapy (regardless of response) was associated with an increase of 0.01246 in EQ-5D index score. Using the German tariff, HRQoL utility scores were estimated for responders and non-responders and applied to the model states (the UK tariff was applied for the UK analysis).

Data on abortive medication use from the last 14 days of the PREVA randomised phase (Table 1) were used to

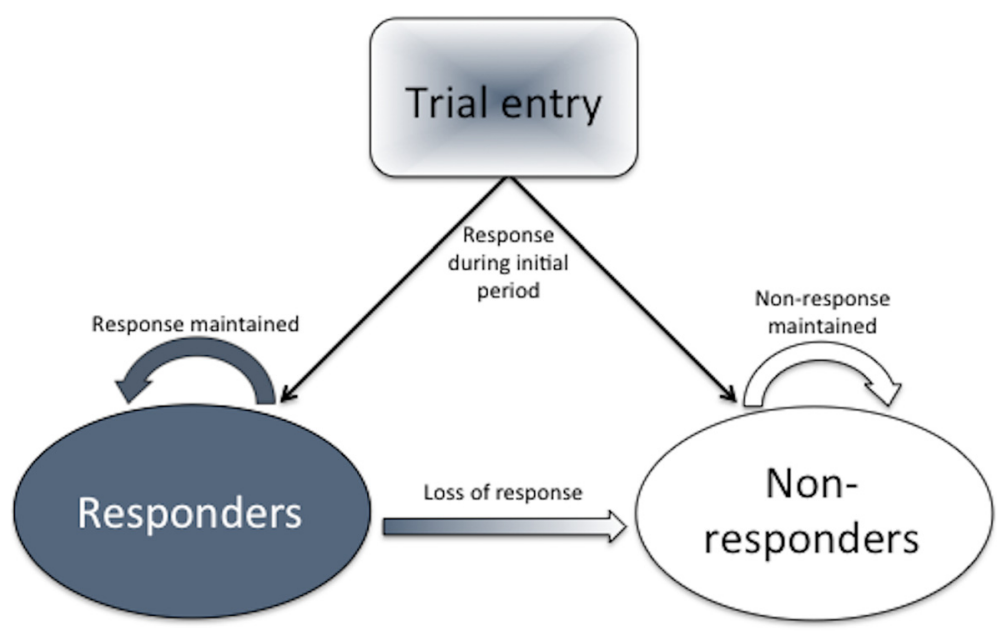

Fig. 2 Pharmacoeconomic model structure. Response was defined as a $\geq 50 \%$ reduction from baseline in the number of $\mathrm{CH}$ attacks during the randomised period (or during month 2 in the case of 4 late responders). Responders in the SoC group were modelled as non-responders beyond the randomised phase. Probability of response was modelled for the base case (response maintained) and for the following alternative scenarios: 1) constant rate of response loss, 2) diminishing rate of response loss, and 3) no initial response in the SoC group. Abbreviations: $\mathrm{CH}$ cluster headache; SoC standard of care 
Table 1 Abortive medication use during the last 14 days of the PREVA randomised phase

\begin{tabular}{lll}
\hline Abortive medication & \multicolumn{2}{l}{ No. of uses, mean (SD) } \\
\cline { 2 - 3 } & $\mathrm{nVNS}+\mathrm{SoC}(n=45)$ & SoC alone $(n=48)$ \\
\hline IN zolmitriptan & $1.6(5.5)$ & $1.3(3.6)$ \\
SC sumatriptan & $2.8(4.0)$ & $7.5(9.6)$ \\
Inhaled oxygen & $6.5(11.1)$ & $10.8(15.3)$
\end{tabular}

Abbreviations: IN intranasal, $n V N S$ non-invasive vagus nerve stimulation, SC subcutaneous, SD standard deviation, SoC standard of care

assess health care resource utilisation. Patients in the $\mathrm{nVNS}+\mathrm{SoC}$ group who maintained responder status were assumed to continue using the same amount of resources as those observed in the overall nVNS + SoC group during the randomised phase. Non-responders were assumed to have the same resource use as that observed in the SoC group during the randomised phase. Unit costs for nVNS, triptans, and inhaled oxygen are shown in Table 2. The nVNS use cost was the listed price in Germany, and unit costs for IN zolmitriptan and SC sumatriptan were determined from the LauerTaxe [19]. Costs for inhaled oxygen were derived using the estimated daily cost for oxygen from a previous study [3] and data from the baseline phase of PREVA.

All economic models are associated with uncertainty; we used a conventional method to reflect this in the analysis by developing a probabilistic model using a Markov chain Monte Carlo simulation to quantify how parameter uncertainty affects model results (i.e. the cost-effectiveness estimates for $\mathrm{nVNS}+\mathrm{SoC})[20,21]$ (Table 3). Distributions for each model parameter of interest were estimated in line with best practice. A probabilistic analysis with 1000 simulations for each scenario was conducted, and mean values from this analysis were calculated. Each simulation was plotted on the cost-effectiveness plane to show the spread of results.

Table 2 Unit cost of treatments

\begin{tabular}{llc}
\hline Treatment & Description & Cost per dose, $€$ \\
\hline IN zolmitriptan & AscoTop Nasal 5 mg/Dosis & $14.07^{\mathrm{a}}$ \\
& Nasenspray, Solution €86.22: & \\
& 6 single-dose nasal sprays, \\
& PZN 03107201 & \\
SC sumatriptan & Sumatriptan-Hormosan Inject & $31.31^{\mathrm{a}}$ \\
& $6 \mathrm{mg} / 0.5$-mL Solution $€ 64.40:$ & \\
& 2 pre-filled syringes, \\
& PZN 04700154 & \\
Inhaled oxygen & Estimated cost per CH attack \\
nVNS & gammaCore device pre-loaded & 2.87 \\
& with 300 stimulations & \\
\hline
\end{tabular}

Abbreviations: IN intranasal, nVNS non-invasive vagus nerve stimulation,

SC subcutaneous

aPrices include mandatory pharmacy discount of $€ 1.77$ per pack

Published prices for zolmitriptan and sumatriptan were taken from Lauer-Taxe (cheapest available price selected) [19]. Price for oxygen was estimated using daily cost from Gaul et al [3]
Table 3 Parameters for the probabilistic sensitivity analysis

\begin{tabular}{llll}
\hline Parameter & Mean & SE & Distribution \\
\hline $\begin{array}{l}\text { Probability of response with } \\
\text { nVNS + SoC }\end{array}$ & 0.489 & 0.074 & Beta \\
$\begin{array}{l}\text { Probability of response with } \\
\text { SoC alone }\end{array}$ & 0.083 & 0.039 & Beta \\
Probability of discontinued response & 0.310 & 0.378 & Normal $^{a}$ \\
Utility score (nVNS + SoC responder) & 0.772 & NA & Multivariate normal \\
Utility score (nVNS + SoC & 0.536 & NA & Multivariate normal \\
non-responder) & & & \\
Utility score (SoC alone responder) & 0.760 & NA & Multivariate normal \\
Utility score (SoC alone & 0.523 & NA & Multivariate normal \\
non-respon) & &
\end{tabular}

non-responder)

Resource use per 14 days

With nVNS + SoC

$\begin{array}{llll}\text { Zolmitriptan } & 1.6 & 0.82 & \text { Gamma } \\ \text { Sumatriptan } & 2.8 & 0.60 & \text { Gamma } \\ \text { Oxygen } & 6.5 & 1.65 & \text { Gamma }\end{array}$

With SoC alone

$\begin{array}{llll}\text { Zolmitriptan } & 1.3 & 0.52 & \text { Gamma }\end{array}$

Sumatriptan $\quad 7.5 \quad 1.38$ Gamma

Oxygen $\quad \begin{array}{lll}10.8 & 2.21 \quad \text { Gamma }\end{array}$

Abbreviations: NA not applicable, $n V N S$ non-invasive vagus nerve stimulation,

$S E$ standard error, SoC standard of care

${ }^{a}$ Based on exponential survival function

\section{Results}

\section{Base case}

For the German base case, the analysis resulted in mean expected costs of $€ 7096.69$ for $\mathrm{nVNS}+\mathrm{SoC}$ and $€ 7511.35$ for SoC alone and mean QALY of 0.607 for nVNS + SoC and 0.522 for SoC alone. Thus, nVNS + $\mathrm{SoC}$ appears to generate greater health benefits for lower overall cost (Table 4). Approximately $80 \%$ of the probabilistic simulations resulted in cost savings for nVNS + $\mathrm{SoC}$ (versus SoC alone), and the vast majority of the simulations plotted fell below the commonly used $€ 20,000 / \mathrm{QALY}$ gained threshold (i.e. the amount that commissioners of health care services are willing to pay per additional unit of health with new technologies)

Table 4 Base case $^{a}$ cost-effectiveness analysis

\begin{tabular}{lccc}
\hline Treatment group & Mean cost,$€$ & Mean QALY & ICER $^{\mathrm{b}}$ \\
\hline nVNS + SoC & 7096.96 & 0.607 & nVNS dominant \\
SoC alone & 7511.35 & 0.522 & over SoC $^{c}$
\end{tabular}

Abbreviations: ICER incremental cost-effectiveness ratio, nVNS non-invasive vagus nerve stimulation, $Q A L Y$ quality-adjusted life-year, SoC standard of care Probabilistic estimates are based on mean results across all Monte Carlo simulations [21]

${ }^{\mathrm{a}}$ In the base case, subjects in the nVNS + SoC group who responded through the extension phase were assumed to maintain response

${ }^{\mathrm{b}}$ The expense of gaining an additional QALY with adjunctive nVNS therapy (vs SoC alone)

Indicates that adjunctive nVNS therapy was more effective and cost saving than SoC alone 
(Fig. 3) [22-24]. Overall abortive medication costs were $23 \%$ lower in the nVNS + SoC group than in the SoCalone group (Fig. 4). Compared with the SoC-alone group, the nVNS + SoC group had $29 \%$ lower SC sumatriptan costs, $19 \%$ lower inhaled oxygen costs, and $75 \%$ higher IN zolmitriptan costs.

\section{Alternative scenarios and sensitivity analysis}

Altering the model by varying the likelihood for loss of response in either group had little effect on the relative cost-effectiveness of nVNS (Table 5). In the alternative scenarios explored, the percentages of the probabilistic simulations that resulted in cost savings for nVNS + SoC (versus SoC alone) were $\sim 71 \%$ for constant rate of response loss and $\sim 79 \%$ for both diminishing rate of response loss and no response for SoC. Results from the sensitivity analysis suggest that exclusion of the 4 late responders to nVNS (i.e. designating them as nonresponders in the model) had a modest impact on costeffectiveness. For all scenarios modelled in the sensitivity analysis, nVNS + SoC was more effective and cost saving (Table 6).

\section{Discussion}

The treatment of $\mathrm{CH}$ is challenging, and many of the commonly used abortive and preventive medications are associated with serious safety risks, poor tolerability, and/or marginal efficacy. For acute treatment, triptans are contraindicated in patients with cardiovascular disease $[25,26]$. Drug costs or restrictions on prescribing and/or coverage may further limit triptan accessibility for many patients [27, 28]. Long-term frequent use of triptans, as may be needed for $\mathrm{cCH}$ management, can in turn lead to the development of medication overuse headache $[29,30]$, which, although rare, has been reported in patients with $\mathrm{CH}[31,32]$. Oxygen may delay rather than abort $\mathrm{CH}$ attacks in some patients and has portability limitations $[25,26]$, and DHE may be associated with fibrosis (e.g. cardiac, pulmonary, pleural), ergotism, and chest tightness [26, 33]. For prophylactic treatment, verapamil has a high potential for drug interactions, and the large dosages required for $\mathrm{CH}$ treatment are associated with adverse cardiac events such as arrhythmias, as well as oedema [26]. Lithium requires progressive titration and frequent drug-level monitoring because of its narrow therapeutic window and the risk

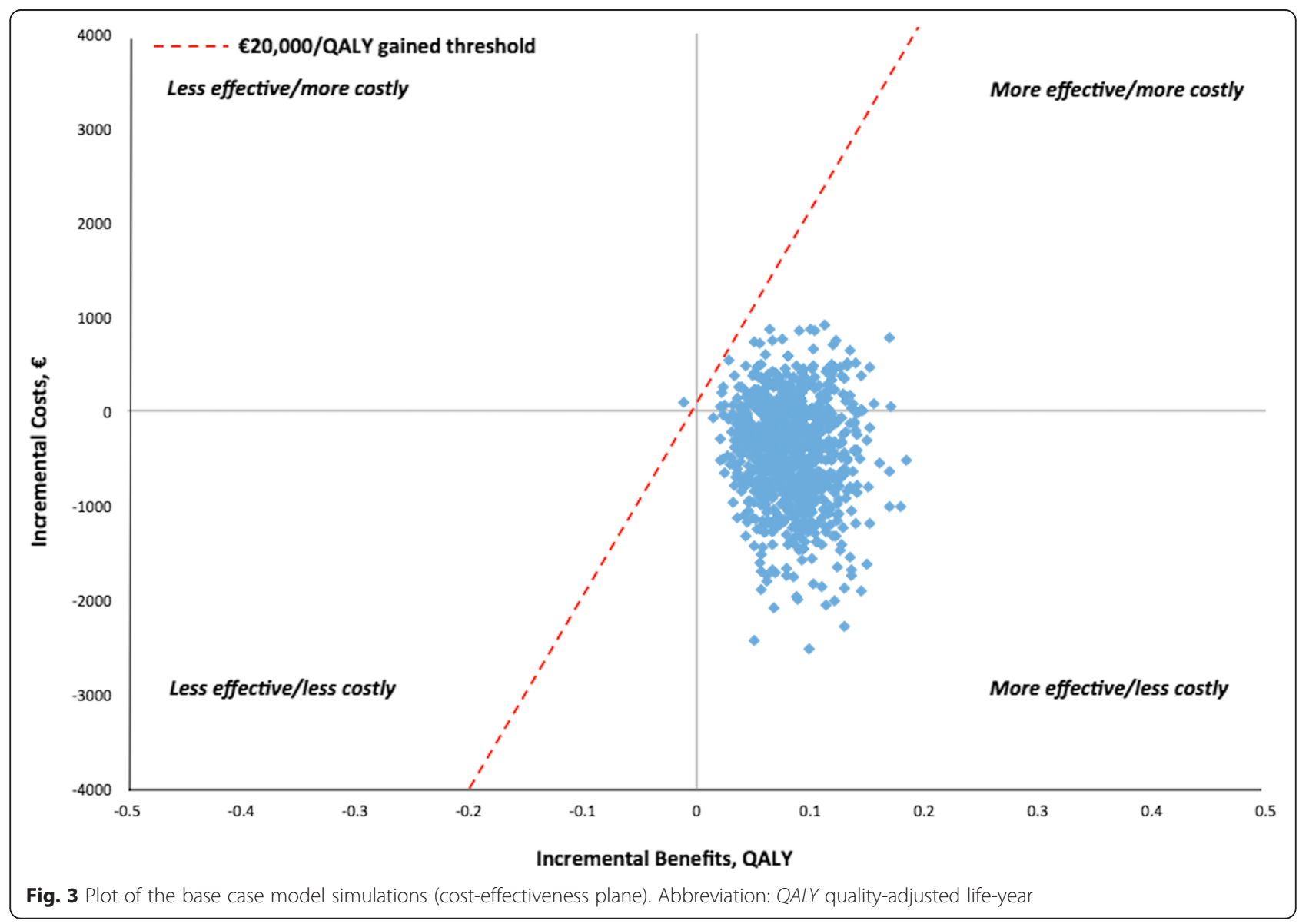




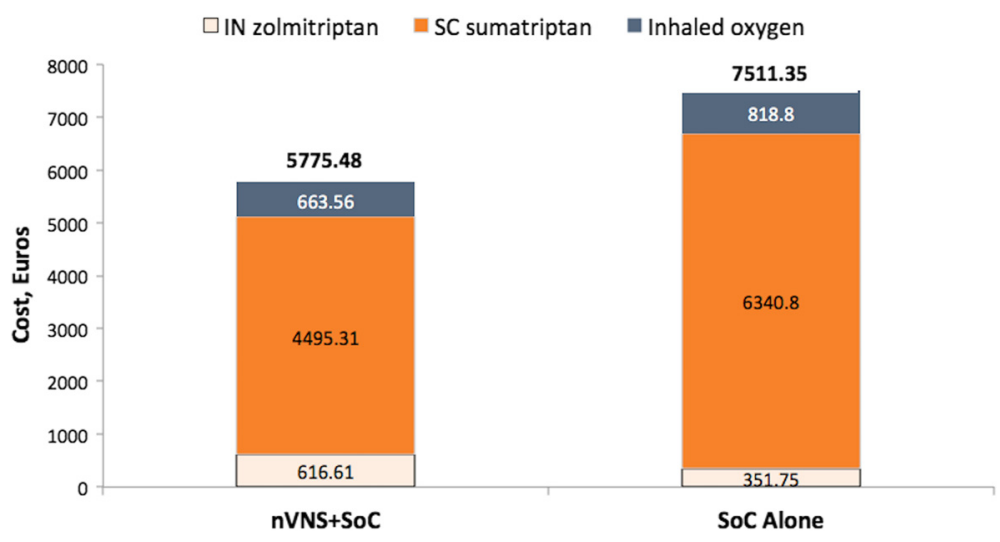

Fig. 4 Breakdown of modelled 1-year costs of abortive medications by category. Abbreviations: IN intranasal; nVNS non-invasive vagus nerve stimulation; SC subcutaneous; SoC standard of care

of toxicity [25, 26, 34], and topiramate is often poorly tolerated owing to its cognitive side effects [26]. Thus, more practical and cost-effective treatment approaches for $\mathrm{CH}$ are needed. Results from the PREVA study [18] suggest that in addition to reducing the frequency of $\mathrm{CH}$ attacks, adjunctive nVNS therapy may decrease the need for abortive medications and improve quality of life in patients with $\mathrm{cCH}$. The current pharmacoeconomic analysis indicates that adjunctive nVNS is likely to result in cost savings when compared with $\mathrm{SoC}$ alone. Notably, the present analysis was conservative in that it included only the costs associated with use of abortive medications without accounting for other potential sources of cost savings (e.g. reduced frequency of clinic visits, fewer hospitalisations, increased productivity).

Table 5 Cost-effectiveness analysis for alternative scenarios

\begin{tabular}{|c|c|c|c|}
\hline \multicolumn{4}{|l|}{ Scenario } \\
\hline Treatment group & Mean cost, $€$ & Mean QALY & ICER $^{a}$ \\
\hline \multicolumn{4}{|c|}{ Constant rate of response loss } \\
\hline nVNS + SoC & 7377.41 & 0.558 & \multirow{2}{*}{$\begin{array}{l}\text { nVNS dominant } \\
\text { over SoC }^{b}\end{array}$} \\
\hline SoC alone & 7518.56 & 0.526 & \\
\hline \multicolumn{4}{|c|}{ Diminishing rate of response loss } \\
\hline nVNS + SoC & 7141.30 & 0.599 & \multirow{2}{*}{$\begin{array}{l}\text { nVNS dominant } \\
\text { over SoC }{ }^{b}\end{array}$} \\
\hline SoC alone & 7508.98 & 0.525 & \\
\hline \multicolumn{4}{|l|}{ No response for SoC } \\
\hline $\mathrm{nVNS}+\mathrm{SoC}$ & 7085.34 & 0.610 & \multirow{2}{*}{$\begin{array}{l}\text { nVNS dominan } \\
\text { over SoC }{ }^{b}\end{array}$} \\
\hline SoC alone & 7507.94 & 0.524 & \\
\hline \multicolumn{4}{|c|}{$\begin{array}{l}\text { Abbreviations: ICER incremental cost-effectiveness ratio, nVNS non-invasive } \\
\text { vagus nerve stimulation, QALY quality-adjusted life-year, SoC standard of care } \\
\text { Probabilistic estimates are based on mean results across all Monte Carlo } \\
\text { simulations [21] } \\
\text { aThe expense of gaining an additional QALY with adjunctive nVNS therapy } \\
\text { (vs SoC alone) } \\
\text { bIndicates that adjunctive nVNS therapy was more effective and cost saving } \\
\text { than SoC alone }\end{array}$} \\
\hline
\end{tabular}

Currently, there are few good options for acute or prophylactic treatment of $\mathrm{CH}$. Neuromodulation methods such as sphenopalatine ganglion (SPG) stimulation and occipital nerve stimulation (ONS) have shown some promise in $\mathrm{CH}$ prevention, but most studies of these techniques have been small and/or have lacked control arms $[35,36]$. Furthermore, SPG and ONS are invasive, expensive, and associated with risks inherent with implanted devices (e.g. infection, pain at the site of implantation, electrode migration). The findings that nVNS is effective in $\mathrm{CCH}$ prophylaxis [18], is not associated with risks that are inherent in invasive neuromodulation methods, and offers cost savings over the current standard practice suggest that this therapy warrants a prominent place in the management of $\mathrm{cCH}$.

The current analysis is subject to certain limitations. The PREVA study provided data from an 8-week period,

Table 6 Cost-effectiveness sensitivity analysis (4 late responders excluded)

\begin{tabular}{|c|c|c|c|}
\hline \multicolumn{4}{|l|}{ Scenario } \\
\hline Treatment group & Mean cost, $€$ & Mean QALY & ICER $^{\mathrm{a}}$ \\
\hline \multicolumn{4}{|l|}{ Response maintained } \\
\hline $\mathrm{nVNS}+\mathrm{SoC}$ & 7380.93 & 0.566 & \multirow{2}{*}{$\begin{array}{l}\text { nVNS dominant } \\
\text { over SoC }\end{array}$} \\
\hline SoC alone & 7540.28 & 0.536 & \\
\hline \multicolumn{4}{|c|}{ Constant rate of response loss } \\
\hline $\mathrm{nVNS}+\mathrm{SoC}$ & 7392.09 & 0.550 & \multirow{2}{*}{$\begin{array}{l}\text { nVNS dominant } \\
\text { over SoC }{ }^{b}\end{array}$} \\
\hline SoC alone & 7440.13 & 0.539 & \\
\hline \multicolumn{4}{|c|}{ Diminishing rate of response loss } \\
\hline $\mathrm{nVNS}+\mathrm{SoC}$ & 7279.89 & 0.560 & \multirow{2}{*}{$\begin{array}{l}\text { nVNS dominant } \\
\text { over SoC }\end{array}$} \\
\hline SoC alone & 7385.29 & 0.537 & \\
\hline
\end{tabular}

Abbreviations: ICER incremental cost-effectiveness ratio, nVNS non-invasive vagus nerve stimulation, $Q A L Y$ quality-adjusted life-year, $S O C$ standard of care ${ }^{a}$ The expense of gaining an additional QALY with adjunctive nVNS therapy (vs SoC alone)

Indicates that adjunctive nVNS therapy was more effective and cost saving than SoC alone 
which were extrapolated to assess cost-effectiveness over 1 year. Although there have been few cost-effectiveness evaluations of neuromodulatory techniques for the treatment of primary headache disorders, such studies have generally included time horizons of at least 3 years [37-39]. Considering the time frame of PREVA, a 1-year time horizon was chosen for this analysis to preserve robustness and to avoid introducing unnecessary uncertainty. As in patients with epilepsy [40], evidence suggests that patients with headache may have improved response to VNS with longer-term treatment [41, 42]. Although increases in response rate with long-term VNS have yet to be explored in $\mathrm{CH}$, the current analysis could be viewed as conservative because the duration of PREVA may not have allowed demonstration of the full benefit of nVNS.

Recently, the National Institute for Health and Care Excellence (NICE) Interventional Procedures Advisory Committee noted that the relapsing/remitting nature of $\mathrm{CH}$ and migraines as well as the potential for placebo effects should be considered when interpreting evidence of treatment efficacy for these conditions [43]. Indeed, because periods of relapse and remission are common among patients with primary headache disorders, research in this area may be susceptible to regression artefacts $[44,45]$. However, the PREVA study included data from patients with $\mathrm{cCH}$ only. By International Classification of Headache Disorders definition [46], $\mathrm{cCH}$ is not associated with extended periods of remission (i.e. $\geq 1$ month), suggesting that the phenomenon of regression to the mean (e.g. aberrantly high attack frequency at baseline followed by a decrease in attack frequency regardless of treatment group) would not be expected. Because the PREVA study lacked a sham treatment group, the degree to which the placebo effect might have contributed to the cost-effectiveness of nVNS is unclear. Nevertheless, the clinically relevant design of the PREVA study was valuable in that it allowed for observation of medication use in a control group that likely reflects real-world use.

As with any probabilistic analysis, some degree of uncertainty is inherent in the current investigation. To address this, a sensitivity analysis and a range of alternative scenarios were included, and results from all of these suggested that $\mathrm{nVNS}+\mathrm{SoC}$ was more effective and cost saving than $\mathrm{SoC}$ alone. Results were relatively insensitive to assumptions about late responders in the nVNS $+\mathrm{SoC}$ arm. In the sensitivity analysis, where the 4 late-responding patients were classified as non-responders, nVNS + SoC was dominant over $\mathrm{SoC}$ alone in all modelled scenarios.

The current analysis cannot be directly extrapolated across all of Europe because it evaluates cost-effectiveness from a German health insurance perspective. To explore the generalisability of our findings, we conducted the same analysis from a UK perspective and found similar results. For the base case, the probabilistic analysis resulted in mean expected costs of $£ 5409.83$ for $\mathrm{nVNS}+\mathrm{SoC}$ and £5393.31 for SoC alone and mean QALY of 0.538 for $\mathrm{nVNS}+\mathrm{SoC}$ and 0.438 for $\mathrm{SoC}$ alone. The incremental cost-effectiveness ratio of nVNS + SoC was $£ 166.12$, and $47 \%$ of the probabilistic simulations resulted in cost savings for $\mathrm{nVNS}+\mathrm{SoC}$ over SoC alone (J. Morris, unpublished data, 2016). The degree to which these results can be generalised to other countries may vary depending on specific drug prices and the availability of generic medications in those markets.

Lastly, the current cost-effectiveness projections included only the costs associated with the use of abortive treatments. This suggests that our analysis is conservative, as data on additional health care resource use (e.g. clinic visits) would likely lead to a disproportionate cost increase for the SoC-alone group. Likewise, potential health benefits from decreased use of abortive medications (e.g. drug-related side effects) and effects on indirect costs (e.g. increased work capacity), which could further enhance the economic profile of nVNS, were not considered herein. The economic benefits of nVNS could be established with greater certainty by incorporating additional cost components into future studies.

\section{Conclusions}

The current study provides evidence of the efficacy and economic benefits of nVNS therapy for patients with $\mathrm{cCH}$ in the context of the German and UK health care systems. In all scenarios modelled, nVNS was more cost-effective than the current standard practice. These findings are especially meaningful given the substantial economic burden associated with $\mathrm{CH}$ [3] and considering that new technologies are cited as major drivers of increasing health care expenditures [47, 48]. Our results suggest that new technologies such as nVNS may help decrease overall treatment costs, information that likely will be important to clinicians, patients, and payers when treatment decisions are made.

\section{Availability of data and materials}

Clinical data from the PREVA study are available in the following publication: Gaul C, et al (2015) Non-invasive vagus nerve stimulation for PREVention and Acute treatment of chronic cluster headache (PREVA): a randomised controlled study [Published online September 21]. Cephalalgia. doi:10.1177/0333102415607070.

Economic data supporting the conclusions in this manuscript are on file at Cogentia Healthcare Consulting Ltd. and electroCore, LLC, and are confidential in order to support economic filings in the affected countries. 


\section{Abbreviations}

cCH: chronic cluster headache; $\mathrm{CH}$ : cluster headache; DHE: dihydroergotamine; HRQoL: health-related quality of life; IN: intranasal; NICE: National Institute for Health and Care Excellence; nVNS: non-invasive vagus nerve stimulation; ONS: occipital nerve stimulation; QALY: quality-adjusted life-year; SC: subcutaneous; SoC: standard of care; SPG: sphenopalatine ganglion; TNC: trigeminal nucleus caudalis; VNS: vagus nerve stimulation.

\section{Competing interests}

James Morris is an employee of Cogentia Healthcare Consulting Ltd. Andreas Straube has received honoraria for educational talks and advisory boards from Allergan Germany; Boehringer Ingelheim; Cerbotech; Desitin Pharma; electroCore, LLC; Hormosan Pharma; MSD Germany; and Teva. Hans-Christoph Diener has received honoraria for participation in clinical trials, contribution to advisory boards, or oral presentations from Addex Pharmaceuticals; Alder Biopharmaceuticals; Allergan, Inc.; Almirall, SA; Amgen, Inc.; AstraZeneca; Autonomic Technologies, Inc.; Bayer Vital; Berlin-Chemie; Boehringer Ingelheim; Bristol-Myers Squibb; Chordate Medical; Coherex Medical; CoLucid Pharmaceuticals, Inc.; electroCore, LLC; GlaxoSmithKline; Grünenthal; Janssen-Cilag; Johnson \& Johnson; Labrys Biologics Inc.; La Roche; Lilly; 3 M; Medtronic; Menarini Pharma; Minster Pharmaceuticals; MSD; NeuroScore; Novartis; Pfizer, Inc.; Pharma Medica Research Inc.; Pierre Fabre Laboratories; Sanofi; Schaper \& Brümmer; St. Jude Medical; Teva; and Weber \& Weber. Financial support for research projects has been provided by Allergan, Inc;; Almirall; AstraZeneca; Bayer; electroCore, LLC; GlaxoSmithKline; Janssen-Cilag; MSD; and Pfizer, Inc. Headache research at the Department of Neurology in Essen is supported by the German Research Council (DFG), the German Ministry of Education and Research (BMBF), and the European Union. Dr. Diener has no ownership interest in and does not own stocks of any pharmaceutical company.

Fayyaz Ahmed has nothing to disclose.

Nicholas Silver has received honoraria from Allergan, Inc., and electroCore, LLC; investigator fees from Amgen Inc. and Eli Lilly and Company; and investigator fees paid to the Walton Centre.

Simon Walker is an employee of Cogentia Healthcare Consulting Ltd. Eric Liebler is an employee of electroCore, LLC, and receives stock ownership.

Charly Gaul has received honoraria from Allergan, Inc; Autonomic Technologies, Inc.; Bayer; Berlin-Chemie; Boehringer Ingelheim; Desitin Pharmaceuticals; electroCore, LLC; Grünenthal; Hormosan Pharma; MSD; and St. Jude Medical. Dr. Gaul has no ownership interests and does not own any pharmaceutical company stocks.

\section{Authors' contributions}

$J \mathrm{M}$ contributed to the design and construction of the pharmacoeconomic model and data analysis and interpretation, as well as to drafting and revision of the manuscript. AS, H-CD, FA, and NS were principal investigators in the PREVA clinical study and provided clinical expertise in data interpretation and revision of the manuscript. SW contributed to the design and construction of the pharmacoeconomic model, data analysis and interpretation, and revision of the manuscript. EL contributed to the design and construction of the pharmacoeconomic model and data interpretation, as well as to drafting and revision of the manuscript. CG was the primary principal investigator in the PREVA clinical study and provided clinical expertise in data interpretation and revision of the manuscript. All authors read and approved the final manuscript draft.

\section{Acknowledgements}

Technical and editorial support for this manuscript was provided by Elizabeth Barton, MS, of MedLogix Communications, LLC, and funded by electroCore, LLC.

\section{Author details}

${ }^{1}$ Cogentia Healthcare Consulting Ltd., Richmond House, 16-20 Regent Street, Cambridge CB2 1DB, UK. ${ }^{2}$ Ludwig Maximilian University of Munich, Marchioninistr 15, Munich D81377, Germany. ${ }^{3}$ Department of Neurology and Headache Center, University Hospital Essen, Hufelandstrasse 55, 45122 Essen, Germany. ${ }^{4}$ Hull and Yorkshire Hospitals, Hull Royal Infirmary, Anlaby Road, Hull HU3 2JZ, UK. ${ }^{5}$ The Walton Centre for Neurology and Neurosurgery, Lower Lane, Liverpool L9 7LJ, UK. ${ }^{6}$ electroCore, LLC, 150 Allen Road, Suite
201, Basking Ridge, NJ 07920, USA. ${ }^{7}$ Migraine and Headache Clinic Königstein, Ölmühlweg 31, 61462 Königstein im Taunus, Germany.

\section{Received: 27 February 2016 Accepted: 7 April 2016 \\ Published online: 22 April 2016}

\section{References}

1. Martelletti P, Mitsikostas DD (2015) Cluster headache: a quasi-rare disorder needing a reappraisal. J Headache Pain 16:59. doi:10.1 186/s10194-015-0545-1

2. Jürgens TP, Gaul C, Lindwurm A, Dresler T, Paelecke-Habermann Y, SchmidtWilcke T, Lürding R, Henkel K, Leinisch E (2011) Impairment in episodic and chronic cluster headache. Cephalalgia 31(6):671-682. doi:10.1177/ 0333102410391489

3. Gaul C, Finken J, Biermann J, Mostardt S, Diener HC, Müller O, Wasem J, Neumann A (2011) Treatment costs and indirect costs of cluster headache: a health economics analysis. Cephalalgia 31(16):1664-1672. doi:10.1177/ 0333102411425866

4. Hedlund C, Rapoport AM, Dodick DW, Goadsby PJ (2009) Zolmitriptan nasal spray in the acute treatment of cluster headache: a meta-analysis of two studies. Headache 49(9):1315-1323. doi:10.1111/j.1526-4610.2009.01518.x

5. D.H.E. 45 [package insert]. Aliso Viejo, CA: Valeant Pharmaceuticals North America; 2014.

6. Holle D, Burmeister J, Scherag A, Ose C, Diener HC, Obermann M, Pred CH Study Group (2013) Study protocol of Prednisone in episodic Cluster Headache (PredCH): a randomized, double-blind, placebo-controlled parallel group trial to evaluate the efficacy and safety of oral prednisone as an addon therapy in the prophylactic treatment of episodic cluster headache with verapamil. BMC Neurol 13:99. doi:10.1186/1471-2377-13-99

7. Francis GJ, Becker WJ, Pringsheim TM (2010) Acute and preventive pharmacologic treatment of cluster headache. Neurology 75(5):463-473. doi:10.1212/WNL.0b013e3181eb58c8

8. Freitag FG, Schloemer F (2014) Medical management of adult headache. Otolaryngol Clin North Am 47(2):221-237. doi:10.1016/j.otc.2013.11.002

9. May A, Leone M, Afra J, Linde M, Sándor PS, Evers S, Goadsby PJ, Force ET (2006) EFNS guidelines on the treatment of cluster headache and other trigeminal-autonomic cephalalgias. Eur J Neurol 13(10):1066-1077. doi:10. $1111 / j .1468-1331.2006 .01566 . x$

10. Beekwilder JP, Beems T (2010) Overview of the clinical applications of vagus nerve stimulation. J Clin Neurophysiol 27(2):130-138. doi:10.1097/WNP. 0b013e3181d64d8a

11. Nesbitt AD, Marin JC, Tompkins E, Ruttledge MH, Goadsby PJ (2015) Initial use of a novel noninvasive vagus nerve stimulator for cluster headache treatment. Neurology 84(12):1249-1253. doi:10.1212/WNL.0000000000001394

12. Yuan H, Silberstein SD (2016) Vagus nerve and vagus nerve stimulation, a comprehensive review: part I. Headache 56(1):71-78. doi:10.1111/head.12647

13. Bossut DF, Maixner W (1996) Effects of cardiac vagal afferent electrostimulation on the responses of trigeminal and trigeminothalamic neurons to noxious orofacial stimulation. Pain 65(1):101-109

14. Oshinsky ML, Murphy AL, Hekierski H Jr, Cooper M, Simon BJ (2014) Noninvasive vagus nerve stimulation as treatment for trigeminal allodynia. Pain 155(5):1037-1042. doi:10.1016/j.pain.2014.02.009

15. Brock C, Errico JP, Simon B, Imthon AK, Drewes A, Aziz Q, Lerman I, Farmer $A D$ (2015) A report on 2 studies of the effects of non-invasive vagus nerve stimulation (nVNS) on autonomic and inflammatory parameters in healthy humans. http://vnsociety.com/wp-content/uploads/2015/11/Brock-2015-WClPoster-A-Report-on-2-Studies-of-the-Effects-of-nVNS-on-Autonomic-andInflammatory-Parameters-in-Healthy-Humans.pdf. Accessed 2 December 2015

16. Levine YA, Koopman FA, Faltys M, Caravaca A, Bendele A, Zitnik R, Vervoordeldonk MJ, Tak PP (2014) Neurostimulation of the cholinergic antiinflammatory pathway ameliorates disease in rat collagen-induced arthritis. PLoS One 9(8):e104530. doi:10.1371/journal.pone.0104530

17. Olofsson PS, Levine YA, Caravaca A, Chavan SS, Pavlov VA, Faltys M, Tracey KJ (2015) Single-pulse and unidirectional electrical activation of the cervical vagus nerve reduces tumor necrosis factor in endotoxemia. Bioelectron Med 2:37-42. doi:10.15424/bioelectronmed.2015.00006

18. Gaul C, Diener HC, Silver N, Magis D, Reuter U, Andersson A, Liebler EJ, Straube A, PREVA Study Group (2015) Non-invasive vagus nerve stimulation for PREVention and Acute treatment of chronic cluster headache (PREVA): a randomised controlled study [Published online September 21]. Cephalalgia. doi:10.1177/0333102415607070 
19. Lauer-Taxe online, available by subscription (2015) http://www.lauer-fischer. de/LF. Accessed March 2015

20. Briggs A, Sculpher M, Claxton K (2006) Decision modelling for health economic evaluation. Oxford University Press, Oxford, UK

21. Drummond MF, Sculpher MJ, Claxton K, Stoddart GL, Torrance GW (2015) Methods for the economic evaluation of health care programmes, 4th edn. Oxford University Press, Oxford, UK

22. Boersma C, Broere A, Postma MJ (2010) Quantification of the potential impact of cost-effectiveness thresholds on Dutch drug expenditures using retrospective analysis. Value Health 13(6):853-856. doi:10.1111/j.1524-4733. 2010.00736.x

23. Brouwer W, van Exel J, Baker R, Donaldson C (2008) The new myth: the social value of the QALY. Pharmacoeconomics 26(1):1-4

24. Simoens S (2010) How to assess the value of medicines? Front Pharmacol 1: 115. doi:10.3389/fphar.2010.00115

25. Martelletti P (2015) Cluster headache management and beyond. Expert Opin Pharmacother 16(10):1411-1415. doi:10.1517/14656566.2015.1052741

26. Pomeroy JL, Marmura MJ (2013) Pharmacotherapy options for the management of cluster headache. Clin Med Insight Ther 5:53-74. doi:10. 4137/CMT.S10251

27. Khan S, Mascarenhas A, Moore JE, Knowles S, Gomes T (2015) Access to triptans for acute episodic migraine: a qualitative study. Headache 55(suppl 4):199-211. doi:10.1111/head.12593

28. Amadio A, Lee K, Yao Z, Camacho X, Knowles S, Lay C, Paterson JM, Hunt J, Gomes T, Ontario Drug Policy Research Network (2015) Public drug coverage and its impact on triptan use across Canada: a population-based study. Headache 55(suppl 4):212-220. doi:10.1111/head.12508

29. Saper JR, Da Silva AN (2013) Medication overuse headache: history, features, prevention and management strategies. CNS Drugs 27(11):867-877. doi:10. 1007/s40263-013-0081-y

30. Silberstein SD Medication overuse headache. http://www. americanheadachesociety.org/assets/1/7/Stephen_Silberstein_-_ Medication_Overuse_Headache.pdf. Accessed 12 January 2016

31. Paemeleire K, Evers S, Goadsby PJ (2008) Medication-overuse headache in patients with cluster headache. Curr Pain Headache Rep 12(2):122-127

32. Goadsby PJ, Cittadini E, Burns B, Cohen AS (2008) Trigeminal autonomic cephalalgias: diagnostic and therapeutic developments. Curr Opin Neurol 21(3):323-330. doi:10.1097/WCO.0b013e3282fa6d76

33. European Medicines Agency (2013) CHMP referral assessment report: ergot derivatives containing medicinal products. http://www.ema.europa.eu/docs/ en_GB/document_library/Referrals_document/Ergot_derivatives-containing_ products/WC500161303.pdf. Accessed 10 November 2015

34. Lee DC, Gupta A (2015) Lithium toxicity. http://emedicine.medscape.com/ article/815523-overview. Accessed 8 February 2016

35. Schoenen J, Jensen RH, Lantéri-Minet M, Láinez MJ, Gaul C, Goodman AM, Caparso A, May A (2013) Stimulation of the sphenopalatine ganglion (SPG) for cluster headache treatment. Pathway $\mathrm{CH}-1$ : a randomized, sham-controlled study. Cephalalgia 33(10):816-830. doi:10.1177/0333102412473667

36. Schwedt TJ, Vargas B (2015) Neurostimulation for treatment of migraine and cluster headache. Pain Med 16(9):1827-1834. doi:10.1111/pme.12792

37. Pietzsch JB, Garner A, Gaul C, May A (2015) Cost-effectiveness of stimulation of the sphenopalatine ganglion (SPG) for the treatment of chronic cluster headache: a model-based analysis based on the Pathway $\mathrm{CH}-1$ study. J Headache Pain 16:530. doi:10.1186/s10194-015-0530-8

38. Jenkins B, Tepper SJ (2011) Neurostimulation for primary headache disorders: part 2, review of central neurostimulators for primary headache, overall therapeutic efficacy, safety, cost, patient selection, and future research in headache neuromodulation. Headache 51(9):1408-1418. doi:10 1111/j.1526-4610.2011.01967.x

39. Leone M, Franzini A, Cecchini AP, Mea E, Broggi G, Bussone G (2009) Costs of hypothalamic stimulation in chronic drug-resistant cluster headache: preliminary data. Neurol Sci 30(suppl 1):S43-47. doi:10.1007/s10072-009-0057-3

40. Elliott RE, Morsi A, Tanweer O, Grobelny B, Geller E, Carlson C, Devinsky O, Doyle WK (2011) Efficacy of vagus nerve stimulation over time: review of 65 consecutive patients with treatment-resistant epilepsy treated with VNS > 10 years. Epilepsy Behav 20(3):478-483. doi:10.1016/j.yebeh.2010.12.042

41. Silberstein SD, Da Silva AN, Calhoun AH, Grosberg BM, Lipton RB, Cady RK, Goadsby PJ, Simmons K, Mullin C, Saper JR, Liebler EJ (2014) Chronic migraine prevention with non-invasive vagus nerve stimulation in a prospective pilot study (the EVENT study): report from the open-label phase. Presented at: 56th Annual Scientific Meeting of the American Headache
Society. June 26-29, 2014. http://www.ecorelibrary.com/landing/pdf/ AHS\%20EVENT\%20Double-blind\%20Poster_PRINT\%206-24-14.pdf

42. Yuan H, Silberstein SD (2015) Vagus nerve stimulation and headache. Headache. doi:10.1111/head.12721

43. National Institute for Health and Care Excellence (2015) Transcutaneous stimulation of the cervical branch of the vagus nerve for cluster headache and migraine. http://www.nice.org.uk/guidance/GID-IP1116/documents/ interventional-procedure-consultation-document. Published November 2015. Accessed 11 January 2016

44. Houle TT, Turner DP, Houle TA, Smitherman TA, Martin V, Penzien DB, Lipton RB (2013) Rounding behavior in the reporting of headache frequency complicates headache chronification research. Headache 53(6): 908-919. doi:10.1111/head.12126

45. Turner DP, Smitherman TA, Penzien DB, Lipton RB, Houle TT (2013) Rethinking headache chronification. Headache 53(6):901-907. doi:10.1111/head.12127

46. Headache Classification Committee of the International Headache Society (2013) The International Classification of Headache Disorders, 3rd edition (beta version). Cephalalgia 33(9):629-808. doi:10.1177/0333102413485658

47. Skinner JS (2013) The costly paradox of health-care technology. MIT Tech Rev http://www.technologyreview.com/news/518876/the-costly-paradox-of-healthcare-technology/. Published September 5, 2013. Accessed 8 December 2015

48. Regalado A (2013) We need a Moore's law for medicine. MIT Tech Rev http://www.technologyreview.com/news/518871/we-need-a-moores-lawfor-medicine/. Published September 3, 2013. Accessed 8 December 2015

\section{Submit your manuscript to a SpringerOpen ${ }^{\circ}$ journal and benefit from:}

- Convenient online submission

- Rigorous peer review

- Immediate publication on acceptance

- Open access: articles freely available online

- High visibility within the field

- Retaining the copyright to your article

Submit your next manuscript at $>$ springeropen.com 